\title{
BEHAVIOUR OF EPOXY SILICA NANOCOMPOSITES UNDER STATIC AND CREEP LOADING
}

\author{
CONSTANTINESCU Dan Mihai \\ professor, Department of Strength of Materials, University POLITEHNICA of Bucharest, Bucharest, \\ Romania,e-mail: dan.constantinescu@upb.ro \\ PICU Radu Catalin \\ professor, Department of Mechanical, Aerospace, and Nuclear Engineering, Rensselaer Polytechnic \\ Institute, Troy, New York, USA, e-mail: picuc@rpi.edu \\ SANDU Marin \\ professor, Department of Strength of Materials, University POLITEHNICA of Bucharest, Bucharest, \\ Romania,e-mail: marin.sandu@upb.ro \\ APOSTOL Dragos Alexandru \\ lecturer, Department of Strength of Materials, University POLITEHNICA of Bucharest, Bucharest, \\ Romania,e-mail: dragos.apostol@upb.ro \\ SANDU Adriana \\ professor, Department of Strength of Materials, University POLITEHNICA of Bucharest, Bucharest, \\ Romania,e-mail: adriana.sandu@upb.ro \\ BACIU Florin \\ associate professor, Department of Strength of Materials, University POLITEHNICA of Bucharest, \\ Bucharest, Romania, e-mail: florin.baciu@upb.ro
}

\begin{abstract}
Specific manufacturing technologies were applied for the fabrication of epoxy-based nanocomposites with silica nanoparticles. For dispersing the fillers in the epoxy resin special equipment such as a shear mixer and a high energy sonicator with temperature control were used. Both functionalized and unfunctionalized silica nanoparticles were added in three epoxy resins. The considered filling fraction was in most cases 0.1, 0.3 and $0.5 \mathrm{wt} \%$.. The obtained nanocomposites were subjected to monotonic uniaxial and creep loading at room temperature. The static mechanical properties were not significantly improved regardless the filler percentage and type of epoxy resin. Under creep loading, by increasing the stress level, the nanocomposite with 0.1 wt\% silica creeps less than all other materials. Also the creep rate is reduced by adding silica nanofillers.
\end{abstract}

Key words: silica nanocomposites, dispersion of nanoparticles, static and creep testing

\section{Introduction}

Polymer nanocomposites have emerged as important structural materials, competing with neat polymers and classical composites. These materials exhibit a combination of exceptional properties which usually cannot be achieved in standard composites. Some of the most studied systems are nanocomposite thermosets, that is polymers filled with nanoparticles and various forms of nano-carbon (carbon nanotubes, graphene, graphene platelets, etc.). In [1], [2], graphene platelets (GPL) and multi-wall carbon nanotubes (MWNT) epoxy composites with various weight fractions ( 0 to $0.5 \mathrm{wt} \%$ ) were prepared, and were tested under monotonic, cyclic (fatigue) and creep conditions. It was observed that the addition of GPL and MWNT has a marginal effect on the stress-strain curve at all strain rates investigated. However, GPL reduces the creep rate at elevated temperatures, especially in the transient creep regime [1]. Both MWNT and GPL lead to a dramatic reduction of crack growth rate under fatigue conditions [2]. In the recently done researches, mechanical testing was performed in order to establish the strength and 
ACTA UIVERSITATIS CIBINIENSIS - TECHNICAL SERIES

Vol. LXIX 2017

toughness properties of different nanocomposites with an epoxy-based matrix [3-5]. Some considerations on the fabrication technology of nanocomposites filled with multi-wall carbon nanotubes (MWNT), alumina $\left(\mathrm{Al}_{2} \mathrm{O}_{3}\right)$ and silica $\left(\mathrm{SiO}_{2}\right)$ nanoparticles were presented.

The influence of the technological methods used to produce nanocomposites was extensively discussed, only as an example in [6]; more than 100 recipes can be found in the literature. Essentially, the main problem is to disperse uniformly the nanofillers, as mentioned in the literature $[7,8]$. Improvements of the manufacturing process were established in order to produce uniformly distributed fillers in the epoxy matrix. On the other hand, [9], it is important to use functionalized nanoparticles that are more compatible with the matrix and hence easier to mix.

It is generally desired that these nanocomposites have superior strength and ductility. The fracture toughness of such nanocomposites can be also improved, as shown [10,3]. As mentioned above and broadly discussed in the literature, the selection of the filling fraction, filler type and filler functionalization has a significant influence on the mechanical properties of the composite.

The influence of the technological procedures to fabricate the nanocomposites was also discussed and will be presented briefly in this paper. Improvements of the manufacturing process of silica $\left(\mathrm{SiO}_{2}\right)$ based nanocomposites are established in order to produce uniformly distributed fillers in the epoxy matrix. The influence of the filler weight percentage and its type are evaluated by establishing the strength and ductility under static testing for the obtained epoxy-based nanocomposites. Besides static loading, creep testing under constant load shows a significant influence of the filler weight percentage of the creep rate and resulting strain.

\section{Methods of fabrication}

For dispersing the fillers in the epoxy resin special equipment is needed. A shear mixer Thinky ARE-250 (Japan) with maximum rotation speed of $2000 \mathrm{rpm}$ was used for mechanical mixing. A high energy sonicator, Sonics VCX-750 (USA), having a generator with $750 \mathrm{~W}$ output, a $20 \mathrm{kHz}$ convertor and a temperature controller, was used to fragment the conglomerated nanoparticles. A programmable vacuum oven Memmert VO 400 (UK) was used for curing. The final mixture of resin, nanofillers and hardener was poured in a silicon mould. For each batch 14 specimens were produced.

Several manufacturing procedures were explored such to improve the dispersion and avoid the formation of air bubbles in the resin. The sample preparation steps that led to the best results are as follows:

- Mixing the resin with the nanoparticles with the shear mixer for 10 minutes at a speed of $1500 \mathrm{rpm}$.

- The resulting solution $\mathrm{R}+\mathrm{NP}(\mathrm{R}=$ resin, $\mathrm{NP}=$ nanoparticles) is sonicated for 2 hours. During sonication, the temperature was maintained at $60{ }^{\circ} \mathrm{C}$ by using a circulating cold water system surrounding the container in which the mixture was sonicated; a temperature gauge was placed inside the mixture for control purposes.

- In Method M1, R+NP was put under a vacuum of 30 mbar for 2 hours at room temperature for degassing. In Method M2 this step was omitted. The hardener $\mathrm{H}(\mathrm{H}=$ hardener) was added to $\mathrm{R}+\mathrm{NP}$ after this step.

- The $\mathrm{R}+\mathrm{NP}+\mathrm{H}$ solution was mixed by hand for about 2 minutes, and poured in the silicon mold.

- The thermal cycle was carried on as prescribed by the producer of the epoxy resin.

\section{Materials used for specimen fabrication}

Various types of resin were used. These include Neukadur EP 986 produced by Altropol Kunststoff GmbH, Germany, which was used together with the hardener Neukadur HN 242 (with a pot time of 25 minutes). Another system considered was the same epoxy with Neukadur HN 246 as hardener (with a pot time of 240 minutes); the second curing agent gives more time for mixing with the resin, degassing and pouring in the mould and was hence preferred.

Furthermore, two epoxy systems produced by BTO Epoxy and named System 2 (S2) and System 5 (S5) were considered. S2 uses a resin notated IR 77.31 and a slow hardener IH 77.15 (with a pot life of 110 minutes at $25^{\circ} \mathrm{C}$ ). S5 is under development and has a low viscosity of $100-300 \mathrm{mPas}$ at $25^{\circ} \mathrm{C}$ and a pot life of 80 minutes at $25^{\circ} \mathrm{C}$.

Both unfunctionalized and functionalized silica nanopowders were used. The unfunctionalized 
ACTA UIVERSITATIS CIBINIENSIS - TECHNICAL SERIES

Vol. LXIX 2017

silica was produced by Sigma Aldrich and had particles of 5-15 nm diameter and purity $99.5 \mathrm{wt} \%$ with some traces of metal.

The functionalized nanopowder was obtained by coupling of azidophenylsilanes to nanosilica with a specific surface area of $175-225 \mathrm{~m}^{2}$ (determined using the Brunauer-Emmett-Teller (BET) theory). This is a fumed silica, with a fractal structure, consisting of particles of approximately 20-80 nm which are agglomerated and intergrown to form bigger aggregates. We decided to use fumed silica since it is the most available type of silica nanopowder, significantly cheaper than e.g. Stöber silica. Fumed silica has a large specific surface area, but much of its surface hydroxyl groups (silanols) are lost during its industrial preparation due to high temperature. We used a non-polar solvent, in order to minimize the intermolecular condensation, and get most of the azidophenyl silanes covalently attached to the silanols present on the silica surface. An acidic catalyst was used in this process. Furthermore, the particles were subjected to a process similar to wet impregnation. In brief, wet ethanolic solutions were prepared by sonication and the solvents were then evaporated to dryness. This procedure is repeated twice. The purpose is to complete the hydrolysis of the silanes, and increase the degree of condensation on the surface of the silica. Functionalized silica is carrying exactly $0.28 \mathrm{mmol}$ of phenylazide per $1 \mathrm{~g}$ of dry particles. Electron microscopy studies and DLS measurements have shown that the aggregates are most commonly 200$500 \mathrm{~nm}$ in size, and they consist of smaller particles, with a broad size distribution $(20-80 \mathrm{~nm})$. The microscopic structure of the nanopowder does not change during the functionalization process. Sonication of the sample is expected to gradually break up the larger aggregates into smaller clusters.

\section{Mechanical testing}

\subsection{Static testing}

Uniaxial traction testing of the specimens was performed using a Zwick/Roell testing machine, model Z010, with a maximum force of $10 \mathrm{kN}$. For each batch 14 specimens were tested to determine the modulus of elasticity, the ultimate tensile strength, and the elongation at failure. Tests were carried on nanocomposites with unfunctionalized and functionalized silica nanopowder. Only few results are presented here. The values shown in the following tables are averages obtained from 14 samples tested for each condition.

The specimens were of ISO 527-2 type 1A and strain was measured with an Epsilon extensometer; in some cases the digital image correlation method (DIC) was also used. DIC was performed using an ARAMIS system and the entire length of each specimen was analyzed. The testing speed was $1.5 \mathrm{~mm} / \mathrm{min}$ which corresponds to an initial strain rate of approximately $10^{-3} \mathrm{~s}^{-1}$.

Weight percentage $\mathrm{wt} \%$ of silica powder was $0.1,0.3,0.5,1.0$, and 3.0 in different batches. The results obtained for samples prepared using method $\mathrm{M} 1$, for which the R+NP mixture was kept under a vacuum of 30 mbar for 2 hours at room temperature for degassing, are presented in Table 1. The results obtained for samples prepared using method M2 (degassing was omitted as it was found that in some cases it generates additional gas bubbles in the specimens) are presented in Table 2.

Table 1: Mechanical properties of nanocomposites obtained with method M1 and containing unfunctionalized nanoparticles

\begin{tabular}{|c|c|c|c|c|}
\hline M1 & $\begin{array}{c}\text { Weight } \\
\text { percentage } \\
{[w t \%]}\end{array}$ & $\begin{array}{c}\text { Longitudinal } \\
\text { modulus of elasticity } \\
{[\mathrm{MPa}]}\end{array}$ & $\begin{array}{c}\text { Ultimate } \\
\text { strength } \\
\text { [MPa] }\end{array}$ & $\begin{array}{c}\text { Elongation at failure } \\
{[\%]}\end{array}$ \\
\hline \multirow{2}{*}{$\begin{array}{c}\text { Pure epoxy (2 } \\
\text { batches) }\end{array}$} & \multirow{2}{*}{$\mathbf{0}$} & 3471 & 71.37 & 2.39 \\
\hline & & 3116 & 77.07 & 4.19 \\
\hline \multirow{3}{*}{$\mathrm{SiO}_{2}$ (silica) } & 0.3 & 3526 & 83.02 & 3.92 \\
\hline & $\mathbf{1}$ & 3633 & 85.74 & 3.65 \\
\hline & 3 & 3438 & 85.02 & 3.82 \\
\hline
\end{tabular}


ACTA UIVERSITATIS CIBINIENSIS - TECHNICAL SERIES

Vol. LXIX 2017

Table 2: Mechanical properties of nanocomposites obtained with method M2 and containing unfunctionalized nanoparticles

\begin{tabular}{|c|c|c|c|c|}
\hline M2 & $\begin{array}{c}\text { Weight } \\
\text { percentage } \\
{[w t \%]} \\
\end{array}$ & $\begin{array}{l}\text { Longitudinal } \\
\text { modulus of elasticity } \\
{[\mathrm{MPa}]}\end{array}$ & $\begin{array}{l}\text { Ultimate } \\
\text { strength } \\
\text { [MPa] }\end{array}$ & $\begin{array}{c}\text { Elongation at failure } \\
{[\%]}\end{array}$ \\
\hline \multirow{2}{*}{$\begin{array}{r}\text { Pure epoxy }(2 \\
\text { batches })\end{array}$} & \multirow{2}{*}{$\mathbf{0}$} & 3910 & 90.00 & 4.35 \\
\hline & & 4815 & 103.98 & 3.35 \\
\hline \multirow{3}{*}{$\mathrm{SiO}_{2}$ (silica) } & 0.1 & 3910 & 82.86 & 4.35 \\
\hline & 0.3 & 3215 & 77.38 & 4.35 \\
\hline & 0.5 & 4230 & 57.95 & 2.15 \\
\hline
\end{tabular}

Similar results are presented in [4]. The elongation at failure is approximately 3-4 \%, the ultimate strength is around $80 \mathrm{MPa}$ - with some increase for pure epoxy M2 - and Young's modulus ranges between 3200 and $3900 \mathrm{MPa}$, with some exceptions (as an example given in Table 2, the strength and stiffness for the second batch of pure epoxy is the average of the results obtained only for two tested specimens). Some variability from sample to sample is observed within given batch. This is due to the presence of gas bubbles and/or silica agglomerates. No systematic effect of the silica nanopowder weight fraction was observed. It was also believed that the use of a commercial epoxy system, for which the chemical content is not entirely known, and of unfunctionalized silica nanopowder may lead to the large scatter in the experimental data.

To address these issues, two specially produced epoxy systems from BTO Epoxy (denoted here as S2 and S5) were used as matrix. Same Sigma Aldrich silica nanopowder with smaller particles of about $5-15 \mathrm{~nm}$ was used to prepare the nanocomposites. In Table 3 are shown the results obtained with the functionalized silica nanopowder.

Table 3. Mechanical properties of nanocomposites obtained with M2 and containing functionalized nanoparticles

\begin{tabular}{|c|c|c|c|c|}
\hline $\begin{array}{l}\text { Epoxy } \\
\text { system }\end{array}$ & Type of material & $\begin{array}{c}\text { Modulus of elasticity } \\
\text { [MPa] }\end{array}$ & $\begin{array}{c}\text { Ultimate strength } \\
{[\mathrm{MPa}]}\end{array}$ & $\begin{array}{c}\text { Elongation at failure } \\
{[[\%]}\end{array}$ \\
\hline \multirow{3}{*}{ S2 } & Pure epoxy & $3371 \pm 138$ & $67.5 \pm 1$ & $3.53 \pm 0.27$ \\
\hline & 0.1 wt $\%$ silica & $3200 \pm 452$ & $66.6 \pm 2.8$ & $3.53 \pm 0.1$ \\
\hline & $0.3 \mathrm{wt} \%$ silica & $3855 \pm 431$ & $60.9 \pm 3$ & $3.0 \pm 0.7$ \\
\hline \multirow{4}{*}{ S5 } & Pure epoxy & $3494 \pm 590$ & $54.1 \pm 6.4$ & $3.14 \pm 0.21$ \\
\hline & $\begin{array}{l}0.1 \text { wt\% silica } \\
\text { (no sonication) }\end{array}$ & $2905 \pm 35$ & $50.1 \pm 0.5$ & $3.95 \pm 0.9$ \\
\hline & $\begin{array}{l}0.5 \text { wt } \% \text { silica } \\
\text { (in resin) }\end{array}$ & $3136 \pm 144$ & $51.2 \pm 0.8$ & $3.25 \pm 0.5$ \\
\hline & $\begin{array}{l}0.5 \text { wt\% silica } \\
\text { (in hardener) }\end{array}$ & $3380 \pm 98$ & $57.4 \pm 1.2$ & $3.3 \pm 0.2$ \\
\hline
\end{tabular}

The epoxy system S5 in pure state has lower mechanical properties than S2, including smaller ultimate strength. Elongations at failure are approximately identical for both pure systems.

The addition of $0.1,0.3$ and $0.5 \mathrm{wt} \%$ does not change significantly the mechanical properties obtained in traction testing at room temperature. S2 with $0.3 \mathrm{wt} \%$ has larger Young's modulus, but the strength and ductility are slightly smaller than for pure epoxy or epoxy with $0.1 \mathrm{wt} \%$ silica. For S5 mixing $0.5 \mathrm{wt} \%$ silica in hardener gives better stiffness and strength than mixing in resin, but elongation at failure is the same. 
At this time mechanical testing of nanocomposites with functionalized silica is under development. Silica nanopowder mixed initially in the hardener and sonicated looks to be a better option in obtaining increased static properties.

\subsection{Creep testing at room temperature}

The loading system of the nanocomposite specimens is shown in Figure 1. A weight $G$ applied at the end of the lever is amplified by the loading system and the traction force $F$ streching the specimen is given by the relation

$F=\frac{b \cdot d}{a \cdot c} \cdot G=8,6 \cdot G$.

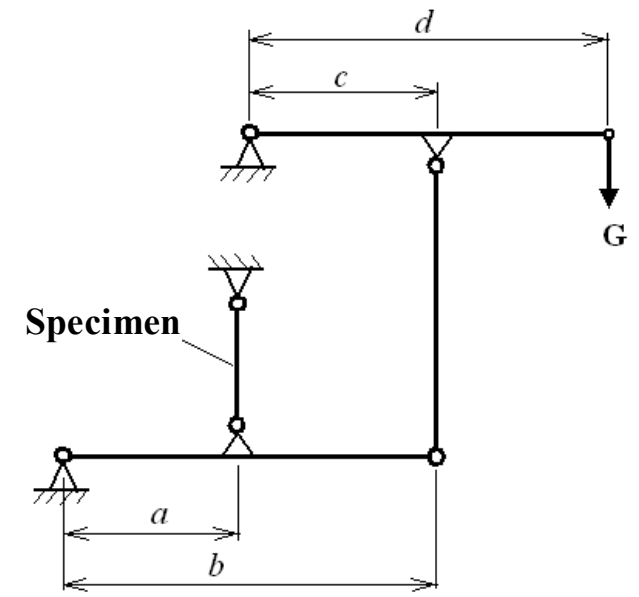

Figure 1: Creep loading system $(a=150 \mathrm{~mm}, b=430 \mathrm{~mm}, c=125 \mathrm{~mm}, d=375 \mathrm{~mm})$

Test were done at room temperature and the influence of the stress level was monitored for both S2 and S5 systems as pure epoxy and folled with same weight percentages of silica. The cross section of the specimens has about $10 \times 4.5 \mathrm{~mm}$ giving an area of $45 \mathrm{~mm}^{2}$. Two loads were applied: 1) $\mathrm{G}=40 \mathrm{~N}$ and 2) $\mathrm{G}=60 \mathrm{~N}$ which induce initial tensile stresses of $\sigma_{0,1}=7.64 \mathrm{MPa}$, respectively $\sigma_{0,2}=11.46 \mathrm{MPa}$. On both sides of the specimen as to eliminate the bending effect two HBM 1-LY18-3/350 strain gauges were placed. The temperature effect was compensated by using an additional strain gauge which was glued on a separate specimen which was not loaded (Figure 2). The strains are aquired using a Spider HBM system and the Catman software. The initial strains were approximated for the two loadings as: 1) $\varepsilon_{0,1}=2000$ $\mu \mathrm{m} / \mathrm{m}$ and 2) $\varepsilon_{0,2}=3000 \mu \mathrm{m} / \mathrm{m}$. These strains were subtracted from the strains measured in time and represented in the figures to follow. 
ACTA UIVERSITATIS CIBINIENSIS - TECHNICAL SERIES

Vol. LXIX 2017

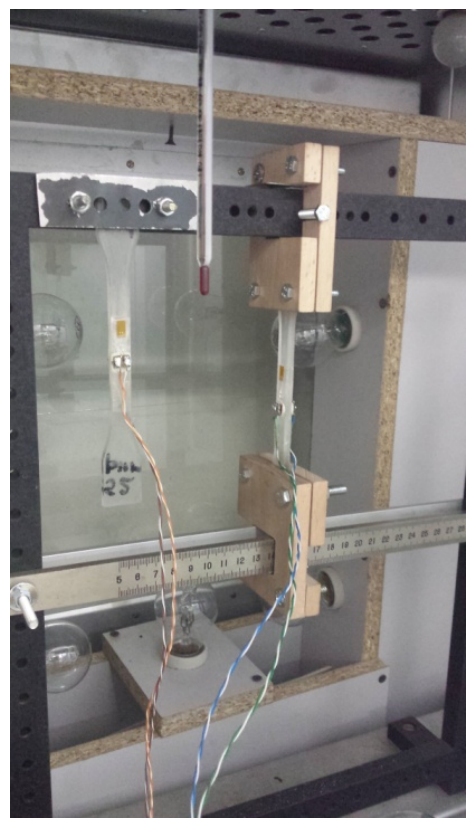

Figure 2: Creep testing and strain measurement with strain gauges

For the two stress levels pure epoxy systems, S2 and S5 are tested. In Figure 3 the variation of strains in time is presented up to more than 17500 seconds, that is about 5 hours.

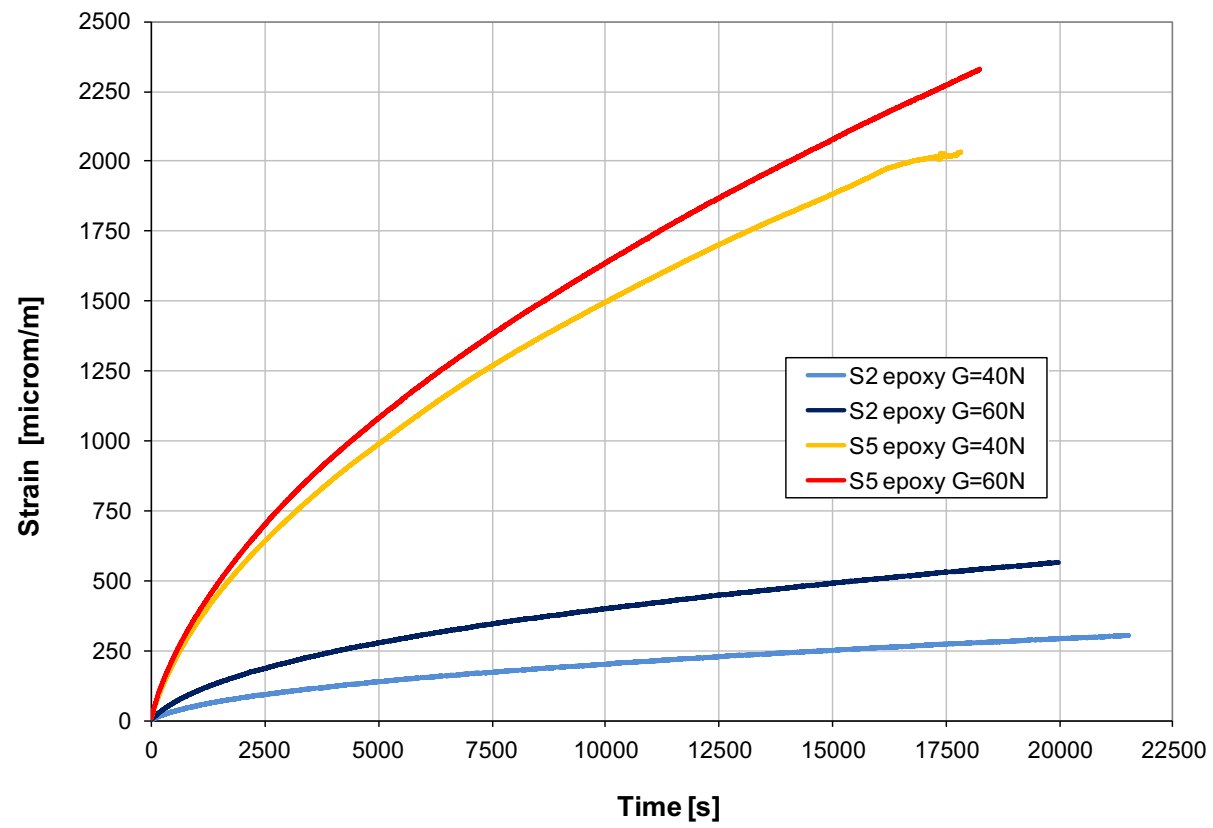

Figure 3: Strains variation for pure epoxy systems S2 and S5

At the beginning, in the primary creep region, measured strains show a non-linear variation as creep is not stabilized. In the secondary stage, when steady-state creep is installed (after about 10000 seconds), the creep rate is almost constant. Clearly, S2 creeps significantly less than S5, but in the same time S2 is more sensitive to the increase of stress level.

If in S2 unfunctionalized silica fillers are added the nanocomposite creeps less (Figure 4), and surprinsingly or not (reffering to the comments done in the first chapter), for $0.1 \mathrm{wt} \%$ silica strains are 
Vol. LXIX 2017

smaller than for $0.3 \mathrm{wt} \%$, that is optimal properties were exhibited at a lower percentage, as also observed in [1].

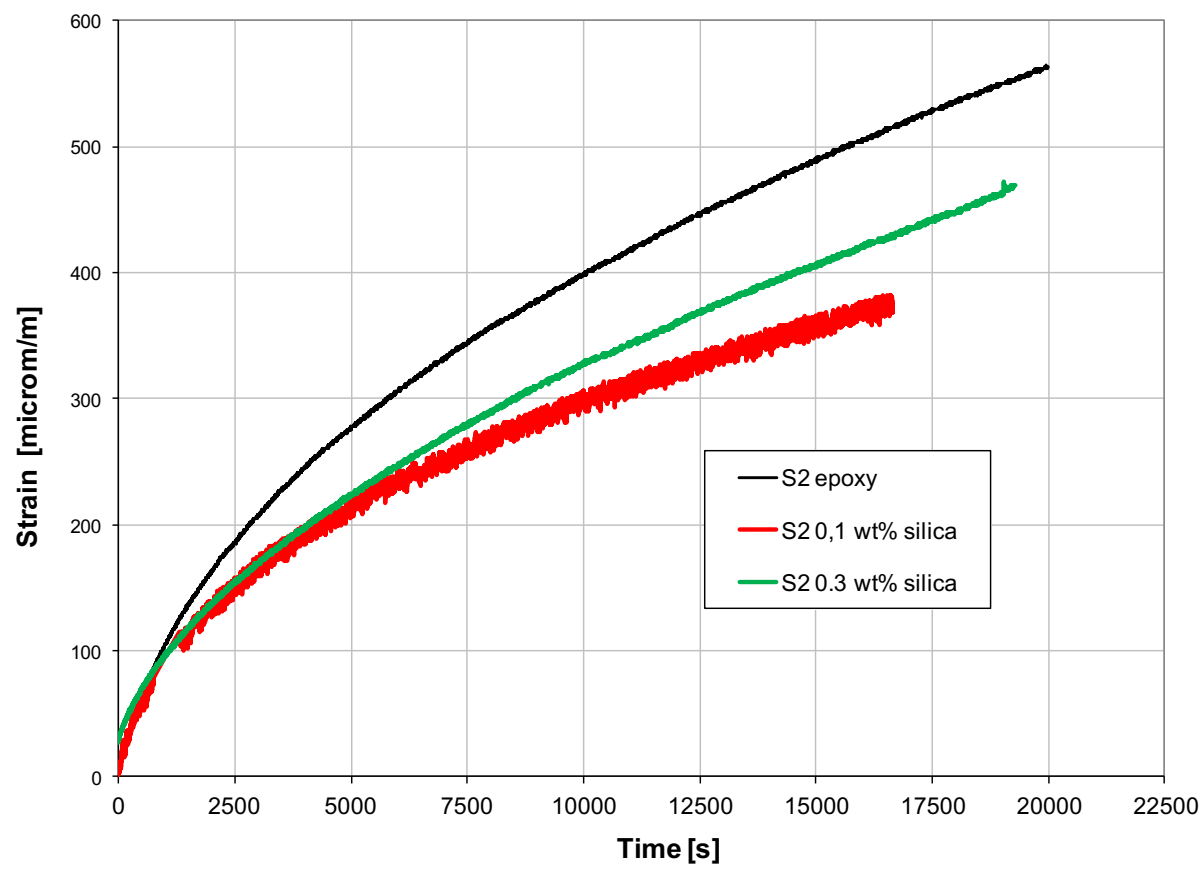

Figure 4: Influence of silica weight percentare on system S2

The presence of silica nanofillers reduces considerably the creep rate. The bigger effect appears for S2 with $0.1 \mathrm{wt} \%$ silica, as for $0.3 \mathrm{wt} \%$ the nanocomposite creeps more in the same amount of time. Such a dependence on the nanofillers percentage was also observed in other nanocomposite systems. It seems that, as mentioned in literature, the optimum mechanical properties for thermoplastic polymers are to be obtained for a filler percentage around $0.1 \mathrm{wt} \%$.

In the primary creep region the strains of the S2 epoxy with $0.1 \%$ silica is only $70 \%$ of that obtained for the pure epoxy. The creep rate in the secondary stage, evaluated as the slope of the interpolated straight lines up to the end of the plots of the strains variation is of $1.1 \times 10^{-8} \mathrm{~s}^{-1}$ for S2 with $0,1 \mathrm{wt} \%$ silica and of $1.47 \times 10^{-8} \mathrm{~s}^{-1}$ for pristine epoxy S2.

\section{Conclusions}

The influence of silica nanofillers added to three epoxy resins is studied for static and creep loading at room temperature. Both unfunctionalized and functionalized silica nanoparticles were added in the pure epoxy. For monotonic static testing of the obtained nanocomposites the influence of different weight percentages of both types of silica fillers on the mechanical properties is not conclusive. We cannot draw a clear conclusion regarding the improvement of the stiffness, strength, and elongation at failure with the increase of weight percentage of silica. When tested for creep, by increasing the stress level, the nanocomposite with $0.1 \mathrm{wt} \%$ unfunctionalized silica creeps less than all other materials, including the neat epoxy. The creep rate is reduced by adding silica nanofillers. The strain reduction is less evident in the primary creep region, but increases in the secondary creep region.

\section{Acknowledgements}

This work was supported by a grant of the Romanian National Authority for Scientific Research and Innovation, CCCDI-UEFISCDI, project number 11/2015. 
ACTA UIVERSITATIS CIBINIENSIS - TECHNICAL SERIES

Vol. LXIX 2017

\section{References}

1. Zandiatashbar, A., Picu, R.C., Koratkar, N., Control of epoxy creep using graphene, Small, Vol. 8, pp. 16751681, doi: 10.1002/smll.201102686, (2012).

2. Zhang, W., Picu, R.C., Koratkar, N., Suppression of fatigue crack growth in carbon nanotube composites, Applied Physics Letters, Vol. 91, 193109, (2007).

3. Picu, C.R., Constantinescu, D.M., Sandu, M., Apostol, D.A., Cosmoiu, I., Toughness enhancement in nanocomposite thermosets with application to carbon-epoxy system, Proceedings of the 13th International Conference on Fracture, Beijing, China, June 16-21, Keynote lecture, (2013).

4. Cosmoiu, I., Apostol, D.A., Picu, C.R., Constantinescu, D.M., Sandu, M., Manufacturing and testing of nanocomposites with carbon nanotubes and nanoparticles, U.P.B. Scientific Bulletin, Vol. 77, pp. 107-119, (2015).

5. Cosmoiu, I., Apostol, D.A., Constantinescu, D.M., Picu, C.R., Sandu, M., Advances on the manufacturing process of nanocomposites with MWNT and nanopowders, Applied Mechanics of Materials, Vol. 760, pp. 281-286, (2015).

6. Zhou, Y., Pervin, F., Lewis, L., Jeelani, S., Fabrication and characterization of carbon/epoxy composites mixed with multi-walled carbon nanotubes, Materials Science and Engineering: A, Vol. 475, pp. 157-165, (2008).

7. Gkikas, G., Barkoula, N.-M., Paipetis, A.S., Effect of dispersion conditions on the thermo-mechanical and toughness properties of multi walled carbon nanotubes-reinforced epoxy, Composites Part B, Vol. 43, pp. 2697-2705, (2012).

8. Montazeri, A., Chitsazzadeh, M., Effect of sonication parameters on the mechanical properties of multi-walled carbon nanotube/epoxy composites, Materials \& Design, Vol. 56, pp. 500-508, (2014).

9. Cui, L.J., Wang, Y.B., Xiu, W.J., Wang, W.Y., Xu, L.H., Xu, X.B., Meng, Y., Li, L.Y., Gao, J., Chen, L.C., Geng, H.Z., Effect of functionalization of multi-walled carbon nanotube on the curing behavior and mechanical property of multi-walled carbon nanotube/epoxy composites, Materials \& Design, Vol. 49, pp. 279-284, (2013).

10. Ayatollahi, M.R., Shadlou, S., Shkrieh, M.M., Fracture toughness of epoxy/multi-walled carbon nanotubes nano-composites under bending and shear loading conditions, Materials \& Design, Vol. 32, 2115-2124, (2010).

11. Constantinescu, D.M., Apostol, D.A., Picu, C.R., Krawczyk, K., Sieberer, M., Mechanical properties of epoxy nanocomposites reinforced with functionalized silica nanoparticles, 2nd International Conference on Structural Integrity, ICSI 2017, 4-7 September 2017, Funchal, Madeira, Portugal, Procedia Structural Integrity, Vol. 5, pp. 647-652, (2017). 